\title{
Research on Task-driven Teaching Method of Computer Teaching
}

\author{
Xiaosen Wen \\ Xijing University, Xi'an, Shaanxi Province, China, 710123
}

Keywords: Computer Teaching, Task-driven Approach, Teaching Method Reform

\begin{abstract}
Computer teaching belongs to the new curriculum teaching. At the same time, different from knowledge transfer, it emphasizes the practicality of knowledge and the proficiency of operation. At present, due to the late beginning of computer teaching in China, most non-computer majors lack relevant computer basic knowledge. Therefore, computer teaching has obvious theoretical and practical significance, which has important strategic significance for the development of social information. Based on the overview of task-driven teaching method, this paper comprehensively analyzes the implementation significance of task-driven teaching method in computer teaching, and then studies the implementation process of task-driven teaching method in computer teaching.
\end{abstract}

\section{Introduction}

Task-driven teaching method is a teaching method based on constructivism teaching theory. The task-driven teaching method is very rich in teaching content. In the process of teaching, it can set up tasks that are both difficult and can promote students' interest in learning. These special tasks can better help students to complete some learning content. At present, this teaching mode has gradually attracted the attention of teachers and students, and has been applied in different disciplines. The task-driven teaching method emphasizes that the student-related learning activities are combined with certain tasks. The traditional teaching mode is to change the teacher's concept of listening to students, and to explore the task to improve the interest of students. The teacher creates learning environment, then lead the students to complete the corresponding tasks, so that students occupy a dominant position in the teaching process. The key point in task-driven teaching is the design of teaching tasks. The design of the teaching tasks must not only enable students to truly learn the knowledge, but also make the students interested in learning, so as to better achieve the driving teaching [1].

\section{The Significance of the Implementation of Task-Driven Teaching Method in Computer Teaching}

In the field of education, computer teaching as an emerging course teaching, with the development of social society, the development of social computer technology has been continuously enriched and perfected, and the contradiction between its teaching methods and teaching tasks has become increasingly prominent. Under the background of this implementation, the traditional computer teaching mode can not meet the needs of computer teaching tasks, and it is necessary to adopt a new and effective teaching mode. The application of task-driven teaching method can make up for this deficiency well, and meet the dynamic requirements of computer courses. It is of great significance in the following four aspects [2].

According to the relevant theoretical knowledge of constructivism, learning is a proactive process in the implementation of task-driven teaching methods in computer teaching. The well-designed learning tasks of teachers can guide students to complete tasks independently. At this time, the task as a "catalyst" of student students' interest can effectively "catalyze" students' computer learning interest and form a benign construction of computer knowledge structure.

In computer teaching, the implementation of task-driven teaching method is task-oriented. The task problem runs through computer teaching. The teaching process is to continuously ask questions, 
analyze problems and solve problems. Students' ability to discover, analyze and solve problems can be effectively cultivated. The mode of task-driven teaching is not a simple mode of teacher-teaching and student acceptance in the traditional sense. It pays more attention to the cultivation of students' self-thinking ability, and requires students to carry out multi-angle and multi-faceted thinking of tasks, so as to effectively cultivate students' problem discovery.

Task-driven pedagogy is implemented in computer teaching. The design of tasks is mostly team tasks, which require students to complete in groups. When students are carrying out tasks, they must constantly consult and communicate with the teachers, and discuss and communicate with the students. The problem analysis ability of the students is improved, and the teamwork spirit in the interaction can be cultivated.

Task-driven pedagogy is implemented in computer teaching. The design of tasks is mostly team tasks, which require students to complete in groups. When students are carrying out tasks, they must constantly consult and communicate with the teachers, and discuss and communicate with the students. The problem analysis ability of the students is improved, and the teamwork spirit in the interaction can be cultivated [3].

\section{The Specific Implementation of Task-Driven Teaching Method in Computer Teaching}

First, create a scenario. The key point of driving task teaching is that the design of the learning task, whether the task design is reasonable and feasible is directly related to the final teaching effect, only the actual teaching situation is very understanding, combined with its own teaching examples, Design a good learning task and improve the quality of teaching. At the same time, the teaching task must be difficult. The teacher must master the difficulty level of the task. If the task design is too easy, there is no specific operability, and the student can easily complete it. The effect of teaching can't play any role. Students can easily get bored with computer students without learning knowledge. They don't want to explore further for deep knowledge points. If it is too difficult for task design, students understand It is difficult to get up, I don't know how to solve it, then I can't stimulate students' enthusiasm for learning, and can't guarantee the quality of computer teaching. For example, in the production of Flash animation, the teacher can use the animation to explain the content, first mention the students' interest in learning, and then the teacher can better explain the knowledge to the students.

First, create a scenario. The key point of driving task teaching is that the design of the learning task, whether the task design is reasonable and feasible is directly related to the final teaching effect, only the actual teaching situation is very understanding, combined with its own teaching examples, Design a good learning task and improve the quality of teaching. At the same time, the teaching task must be difficult. The teacher must master the difficulty level of the task. If the task design is too easy, there is no specific operability, and the student can easily complete it. The effect of teaching can't play any role. Students can easily get bored with computer students without learning knowledge. They don't want to explore further for deep knowledge points. If it is too difficult for task design, students understand It is difficult to get up, I don't know how to solve it, then I can't stimulate students' enthusiasm for learning, and can't guarantee the quality of computer teaching. For example, in the production of Flash animation, the teacher can use the animation to explain the content, first mention the students' interest in learning, and then the teacher can better explain the knowledge to the students [4].

Third, autonomous learning and discussion. In the process of teaching, the teacher guides the students to learn independently, and has the right time for the students to discuss each other, exchange ideas through the students themselves, and put forward their own opinions on the learning methods and the content of the learning. Suggest. For example, after the teacher has arranged a certain task, after a certain period of time, after the students have already had ideas for their own production works, the teacher can let the students exchange the difficulties encountered or some special ones they found. In the effect of POWERPOINT braking dynamics, the selection of the background of the picture, the insertion of the content, the switching of the previous page and the next page of the slide, etc., the students have problems in the communication and communication 
among the students. It can also be put forward in time. Understand that good students can answer these questions directly from the perspective of students. The places that they don't understand can also understand quickly. Compared with the teacher's explanation from the perspective of teaching, the students also accept it. It is also easier. Direct communication and communication between students is also better to promote the growth of students' learning ability and increase the amount of knowledge reserves.

Autonomous learning and discussion. In the process of teaching, the teacher guides the students to learn independently, and has the right time for the students to discuss each other, exchange ideas through the students themselves, and put forward their own opinions on the learning methods and the content of the learning. Suggest. For example, after the teacher has arranged a certain task, after a certain period of time, after the students have already had ideas for their own production works, the teacher can let the students exchange the difficulties encountered or some special ones they found. In the effect of POWERPOINT braking dynamics, the selection of the background of the picture, the insertion of the content, the switching of the previous page and the next page of the slide, etc., the students have problems in the communication and communication among the students. It can also be put forward in time. Understand that good students can answer these questions directly from the perspective of students. The places that they don't understand can also understand quickly. Compared with the teacher's explanation from the perspective of teaching, the students also accept it. It is also easier. Direct communication and communication between students is also better to promote the growth of students' learning ability and increase the amount of knowledge reserves [5].

On the basis of reasonable task setting, the students' self-learning interest can be effectively stimulated. At this time, the implementation of the task is completed, and the teacher is not allowed to instill all the teaching contents into the students, but the main purpose is to train the students to assist the spirit. Correctly grasp the degree of computer knowledge professors and independent exploration, carry out group assignment activities for task implementation, and leave room for development for students' independent learning, teamwork, and joint consultation. Therefore, in computer classroom teaching, the teacher only acts as a guiding role, giving students guidance on relevant issues at the appropriate time, taking the students as the main body for classroom teaching, and promoting students to set tasks on the basis of relevant theoretical knowledge. For example, when learning the use of a computer software, the teacher asks the students to conduct a group discussion after setting the task, and obtains the use method of the software, so that the students can obtain a real learning experience and a sense of accomplishment, thereby stimulating the students' knowledge of the computer.

When students implement computer-related tasks, teachers should vigorously carry out exchanges and discussions on teaching tasks. In the discussion about the task, the main purpose of the student's self-exploration spirit is to help students find problems and solve problems in communication, learn from each other's strengths, brainstorm ideas, and jointly implement the implementation and development of teaching tasks. In the task discussion session, in order to realize the cultivation of students' independent inquiry spirit, the guidance effect of teachers is the key to the improvement of students' learning quality, and it is the necessary guarantee for the complete completion of computer teaching quality. Therefore, in the task discussion session of computer teaching, teachers should guide them reasonably, and adopt a way of not directly clarifying and not letting them go wrong, gradually guiding students to discover problems themselves, analyzing and deepening problems, and finally solving problems. Realize the expected goal of communication discussion, that is, to realize the cultivation of students' self-inquiring spirit.

\section{Conclusion}

At present, China's information technology is constantly developing, and the number of users of computers is constantly rising. In the context of computer teaching, higher requirements are also put forward. In this context, the driving task method is recognized by more and more educational institutions, and applied to practical teaching, through the driving of teaching in computer teaching. 
Application improves the teaching quality of computer teaching, and provides a reference for the better use of this teaching mode in other disciplines in the future.

\section{References}

[1] Yang Jianxun. Implementation of Task-Driven Teaching Method in Computer Teaching [J]. Education and Occupation, 2013.

[2] Gao Shuran. Implementation and Application of Task-Driven Teaching Method in Computer Teaching [J]. Science and Technology, 2015.

[3] Zhang Min. Implementation of task-driven teaching method in computer teaching [J]. Electronic Production, 2015.

[4] Chen Yimei. Application Research of Task-Driven Teaching Method in Computer Teaching of Secondary Vocational Schools[J].Journal of Lanzhou College of Education,2016(04):115-116.

[5] Zhang Shengzhen. Optimization of Computer Teaching in Higher Vocational Education under Task-Driven Teaching[J]. Information and Computer, 2016(04): 203+205. 